\title{
INFLUENCE OF SURFACE EMISSIVITY AND OF LOW EMISSIVITY SHIELDS ON THE THERMAL PROPERTIES OF LOW DENSITY INSULATING MATERIALS
}

\author{
Arduini M. \\ Bavarian Center for Applied Energy Research \\ Wurzburg, Germany \\ Campanale M. ${ }^{1}$, Moro L. \\ Dipartimento di Fisica Tecnica \\ Università degli Studi di Padova \\ Padova, Italy \\ E-mail: manuela.campanale@unipd.it
}

\section{ABSTRACT}

The theory of heat transfer through low density insulating materials explains the importance of thermal radiation in the overall heat transfer. As a matter of fact, in many semitransparent insulating materials, radiation has a considerable influence on measured thermal conductivity. In this work we continue the investigation (both experimentally and theoretically) on the heat transfer through low density insulating materials that we started some years ago and whose results have been presented in some International Conferences. Test have been done on low density insulating materials: expanded polystyrene with a density of $10 \mathrm{~kg} / \mathrm{m}^{3}$ and polyester fibres with a density of $9 \mathrm{~kg} / \mathrm{m}^{3}$ (these last tests are not yet completed and will not be discussed in this paper). The transfer factor $\mathcal{T}$ was measured in the heat flow meter apparatus of our laboratory [1]. The first measurements have been done with the two surfaces of the apparatus uncoated (emissivity $\varepsilon=0.91$ ) at a mean test temperature of $283 \mathrm{~K}(10$ $\left.{ }^{\circ} \mathrm{C}\right)$ and then with the specimens enclosed in the aluminium foils (emissivity $\varepsilon=0.045$ ) at the same mean test temperature. The results obtained from the measurements of the transfer factor $\mathcal{T}$ pointed out that a change of the emissivity $\varepsilon$ of the surfaces from 0.91 to 0.045 caused a considerable decreasing of the transfer factor. Then the same panels have been cut into two slices and the aluminium foil has been interposed also between the slices, as shield, and the transfer factor was measured again in both cases: at first with the surfaces of the apparatus uncoated and then with the surfaces of the apparatus coated with the aluminium foils. In both cases the decreasing of the transfer factor $\tau$ was not negligible. The radiation extinction parameters have been then measured with a spectrometer and a model has been found to predict the transfer factor $\mathcal{T}$ in function of the testing conditions. We can conclude that in presence of a thin reflective metal cover placed on a low density insulating material, the thermal
\end{abstract}

conductivity decrease immediately (about 7\%) with a significant improvement of the thermal characteristics of the insulating material. If we put then some low emissivity foils between the slices of the material, another considerable decreasing of the thermal conductivity can be obtained (about $10 \%$ ) and in presence of both aluminum foils (inside and outside). This fact confirms the importance of the contribution of radiation in thermal transmissivity of low density insulating materials and gives the possibility to reduce and to predict the thermal performances

\section{INTRODUCTION}

In these last years, environmental problems forced the manufacturers to change the blowing agents of some insulating materials containing CFCs. As a consequence of this fact the thermal properties of many insulating materials worsened. According with this fact, a lot of work has been done by the researchers to find alternative materials and innovative methods to improve the thermal performances of already existing materials.

In this paper we investigated the possibility to decrease significantly the thermal conductivity of a low density expanded polystyrene by reducing the radiative fraction of the total heat transfer crossing the material.

\section{NOMENCLATURE}

\begin{tabular}{|c|c|c|}
\hline$A$ & {$[\mathrm{~W} /(\mathrm{m} \cdot \mathrm{K})]$} & Conductivity of the gas enclosed in the materia \\
\hline$B^{\prime}$ & {$\left[\mathrm{m}^{3} / \mathrm{kg}\right]$} & Conductive parameter \\
\hline$d$ & {$[\mathrm{~m}]$} & Specimen thickness \\
\hline$N$ & {$\left[\mathrm{~m}^{-1}\right]$} & Scattering coefficient \\
\hline$P$ & {$\left[\mathrm{~m}^{-1}\right]$} & Absorption coefficient \\
\hline$R$ & {$\left[\mathrm{~m}^{2} \cdot \mathrm{K} / \mathrm{W}\right]$} & Thermal resistance \\
\hline$S^{\prime}$ & {$\left[\mathrm{m}^{2} / \mathrm{kg}\right]$} & Mass extinction parameter \\
\hline$t$ & {$\left[{ }^{\circ} \mathrm{C}\right]$} & Temperature \\
\hline$T$ & {$[\mathrm{~K}]$} & Absolute temperature \\
\hline
\end{tabular}


Special characters

$\begin{array}{lll}\varepsilon & {[-]} & \text { Emissivity } \\ \lambda & {[\mathrm{W} / \mathrm{m} \cdot \mathrm{K}]} & \text { Thermal conductivity } \\ \rho & {\left[\mathrm{kg} / \mathrm{m}^{3}\right]} & \text { Density } \\ \sigma_{n} & {\left[\mathrm{~W} / \mathrm{m}^{2} \cdot \mathrm{K}^{4}\right]} & \text { Stefan Boltzmann constant } \\ \mathcal{T} & {[\mathrm{W} /(\mathrm{m} \cdot \mathrm{K})]} & \text { Transfer factor } \\ \omega & {[-]} & \text { Albedo }\end{array}$

Subscripts

$\begin{array}{ll}c & \text { Conductive } \\ m & \text { Mean } \\ r & \text { Radiative } \\ t & \text { Total } \\ \Lambda & \text { Rosseland }\end{array}$

\section{THEORETICAL MODEL}

The behaviour of almost all insulating materials may be described with a good accuracy if they are considered as an homogeneous semitransparent medium. It is well known that any model for the study of the heat transfer in such a semitransparent medium shall consider the elementary processes of conduction in the gas enclosed in the cell, conduction through the solid matrix, radiation and convection [2, 3, 4]. This last one may actually be disregarded, as demonstrated, due to the very small size of the cells. The analytical treatment of combined radiation and conduction heat transfer is rather complex, so that simplifying assumptions are always needed. The non-linear relationship of radiation heat transfer with temperature is the main difficulty in solving the equations describing heat transfer by combined conduction and radiation [5, 6] (emitted, absorbed and scattered). To model radiation heat transfer, the so called "two flux model" is a very good compromise between simplicity of the model and accuracy in the interpolation and prediction of experimental results, The "two flux model" starts from the simplifying assumption that all radiation beams crossing a plane in all possible direction can be grouped in those crossing the plane from left to right and those crossing the plane from right to left. In this way all the radiation crossing the plane is reduced to a forward radiation intensity and a backward radiation intensity.

The theory of heat transfer through semi-transparent insulating materials explains the importance of thermal radiation in the overall heat transfer. As a matter of fact, in many semitransparent insulating materials, the influence of radiation is such that the boundaries surface emissivity $\varepsilon$ has a considerable influence on measured thermal conductivity. If we consider layers of a semitransparent homogeneous material and we measure the thermal resistance, $R$, on specimens of increasing thickness, while keeping unchanged all other testing conditions (mean test temperature, $T_{\mathrm{m}}$, temperature difference and emissivity, $\varepsilon$, of apparatus surfaces), the resulting plot of thermal resistance, $R$, as a function of slab thickness, $d$, differs from the straight line that should result for a purely conducting material (see Figure 1) even though there is still a straight portion beyond the thickness $d_{\infty}$. The thickness $d_{\infty}$ indicates the beginning of the straight portion of the plot of thermal resistance, $R, \lambda_{\mathrm{t}}$ represents the thermal

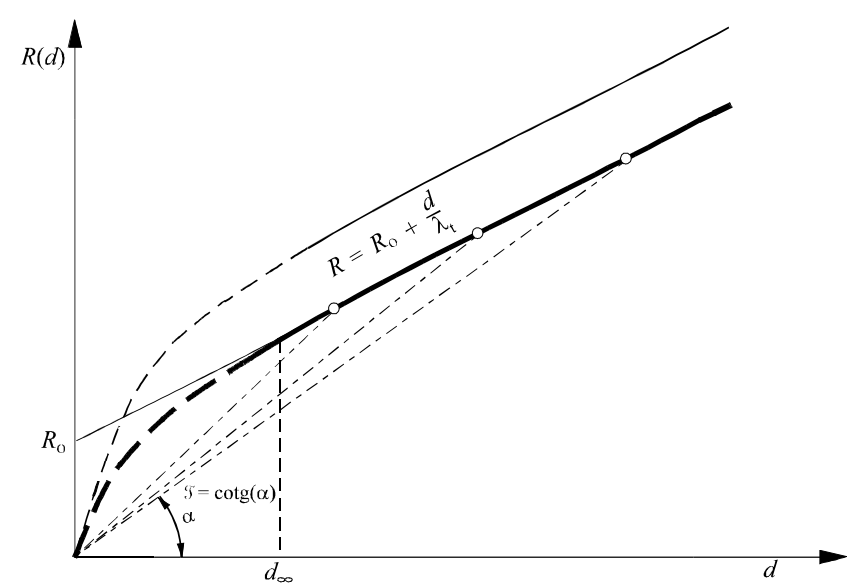

Figure 1 Thermal resistance $R$ as a function of the specimen thickness $d$.

transmissivity. A reduction in the emissivity of the surfaces of the apparatus in contact with the specimen shifts upwards the bold line.

The thermal resistance of a flat specimen of low density material may be expressed through a mathematical model as: $R=R_{0}+d / \lambda_{\mathrm{t}}$ where $R_{0}$ is a factor that depends on many other parameters included the emissivity $\varepsilon$ of the surfaces, $d$ is the thickness of the specimen while $\lambda_{t}$ is the transmissivity, that may considered the sum of two terms: $\lambda_{\mathrm{c}}$ and $\lambda_{\mathrm{r}}$. The first one $\lambda_{\mathrm{c}}$ is the thermal conductivity due to the heat transfer in the solid matrix and in the gas enclosed in cells or among the fibres and $\lambda_{\mathrm{r}}$ is the heat transfer due to radiation. It is possible to write:

$\lambda_{\mathrm{t}}=\lambda_{\mathrm{c}}+\lambda_{\mathrm{r}}$

$\lambda_{\mathrm{c}}$ may be written in the following way as the sum of the term due to conduction in the solid matrix $B \rho$, proportional to the bulk density $\rho$ and the one $A$ due to the conduction in the gas:

$\lambda_{\mathrm{c}}=A+B \rho=A\left(1+B^{\prime} \rho\right)$

$A$ is the conductivity of the gas enclosed in the insulating materials and $B$ is a parameter which takes the conduction in the solid matrix into account.

$\lambda_{\mathrm{r}}$ may be written as:

$\lambda_{\mathrm{r}}=\frac{4 \sigma_{\mathrm{n}} T_{\mathrm{m}}^{3}}{\frac{S^{\prime} \rho}{2}}$

$\sigma_{\mathrm{n}}=5.67 \cdot 10^{-8} \mathrm{~W} /\left(\mathrm{m}^{2} \cdot \mathrm{K}^{4}\right)$ is the Stefan Boltzmann's constant, $T_{\mathrm{m}}$ is the mean test temperature in kelvin and $S^{\prime}$ is a mass extinction coefficient due to combined scattering and absorption.

In this way Equation 1 becomes: 
$\lambda_{\mathrm{t}}=A\left(1+B^{\prime} \rho\right)+\frac{4 \sigma_{\mathrm{n}} T_{\mathrm{m}}^{3}}{\frac{S^{\prime} \rho}{2}}$

We can also introduce the transfer factor $\mathcal{T}$ defined as the ratio between the thickness $d$ and the thermal resistance $R$. It is dimensionally equivalent to a thermal conductivity and is frequently called "measured" or "apparent" thermal conductivity that we can obtain with a measurement. The transfer factor $\tau$ may be written also in the following way:

$$
\tau=\lambda_{\mathrm{t}} \frac{1}{1+\frac{\lambda_{\mathrm{t}} R_{0}}{d}}
$$

For the straight portion of $R$ versus $d$ of Figure 1 equation 5 allows to understand the so called "thickness effect" [7, 8], i.e. the influence of specimen thickness on the value of the transfer factor $\mathcal{T}$ on low density insulations. The transfer factor becomes equal to $\lambda_{t}$, which is an intrinsic property of the medium, when $d \rightarrow \infty$ only (i.e. at large thicknesses, when the slope of dashed and dotted segments of Figure 1 becomes constant).

The thermal characteristics of the material depend on the values of the parameters appearing in equation 4 , these values have to be identified and it is important to point out the meaning of the above terms:

- A represents the conductivity of the gas enclosed in the cells. If the gas is air it is possible to use the following expression:

$\lambda_{\mathrm{g}}=A=\lambda_{\text {air }}\left(1+0.003052 \cdot t_{\mathrm{m}}-1.286 \cdot 10^{-6} t_{\mathrm{m}}{ }^{2}\right)$

where $t_{\mathrm{m}}$ is the mean test temperature in ${ }^{\circ} \mathrm{C}$ while $\lambda_{\text {air }}=$ $0.0242396 \mathrm{~W} /(\mathrm{m} \cdot \mathrm{K})$ represents the thermal conductivity of the air at $0^{\circ} \mathrm{C}$.

- $S=S^{\prime} \rho$ is the extinction coefficient due to combined absorption and scattering. $S=P+2 N$ where $P$ is the extinction due to absorption and $2 N$ is that due to scattering. This parameter may be temperature dependent.

The first order approximation $S^{\prime}=S^{\prime}{ }_{0}\left(1+T C O t_{\mathrm{m}}\right)$, where $S^{\prime}{ }_{0}$ is the value of $S^{\prime}$ at $0^{\circ} \mathrm{C}$ and $T C O$ the temperature coefficient of $S^{\prime}$, has proved to be sufficiently accurate for the purpose of this work.

- $B^{\prime}$ is a parameter used to identify the conduction in the solid matrix of the material. It should remain within the two limit values according to the distribution of the materials (in the struts or in the walls of the cells) for cellular materials [9].

The model described was adopted to analyze common insulating materials: here we will concentrate on the behaviour of low density cellular plastic materials to investigate the influence on the measured transfer factor $\mathcal{T}$ of the different emissivity $\varepsilon$ of the boundary surface.

\section{EXPERIMENTAL WORK}

To be able to evaluate the variation of the contribution due to conduction and due to radiation on the total heat transfer in low density insulating materials, a series of measurement has been done. Experimental data were obtained using the heat flow meter apparatus of our laboratory whose accuracy is about $\pm 1 \%$ and whose reproducibility is better than $\pm 0.3 \%$.

At the beginning of this research work, three years ago, some measurements were made also on an extruded polystyrene with a density of $51 \mathrm{~kg} / \mathrm{m}^{3}$ and on an expanded polystyrene with a density of $21 \mathrm{~kg} / \mathrm{m}^{3}$, but it was immediately clear that the different emissivity of the surfaces did not influence the thermal behaviour of the material in the first case or had a very low influence in the second case $[10,11]$. On the contrary, we realized that the different emissivity of the surfaces has a big impact on the thermal behaviour low density insulating material.

The first set of measurements of the transfer factor $\mathcal{T}$ has been performed on five different low density expanded polystyrene boards $\left(9.6 \mathrm{~kg} / \mathrm{m}^{3}\right)$ at a mean test temperature of $283 \mathrm{~K}$ and with a temperature difference, between the main surfaces, of $20{ }^{\circ} \mathrm{C}$. The dimensions of the specimens were 50 $\mathrm{cm} \times 50 \mathrm{~cm}$ with a thickness of about $10 \mathrm{~cm}$. The choice of thick specimens was made to avoid the above mentioned "thickness effect". In this case the measured transfer factor $\mathcal{T}$ may be considered equal to the thermal transmissivity of the material $\lambda_{\mathrm{t}}$. All the measurements have been done in the same heat flow meter apparatus, at first with the two main surfaces of the apparatus in contact with the specimen uncoated (emissivity of the surfaces $\varepsilon=0.91$ ) and successively the same surfaces covered with aluminium reflective foils (emissivity $\varepsilon$ $=0.045$ ). The results obtained from the measurements of the transfer factor $\mathcal{T}$ pointed out that a change of the emissivity of the main surfaces caused a decreasing of the transfer factor about $7 \%$ as summarized in following Table 1

The second set of measurements of the transfer factor was made after cutting horizontally each of the five specimens in two equal slices and then interposing an aluminium foil between the two slices, as a shield. The purpose was to investigate the change of the thermal performance of the material. The results are summarized in Table 2: the decreasing of the transfer factor in this case is about $10 \%$.

Table 1 Effect of the emissivity on expanded polystyrene: aluminium foils on the external surfaces

\begin{tabular}{|c|c|c|c|}
\hline $\begin{array}{c}\text { Specimen } \\
\text { number }\end{array}$ & $\begin{array}{c}\text { Measured transfer } \\
\text { factor } \mathcal{T} \text { without } \\
\text { aluminium foils } \\
{[\mathrm{W} /(\mathrm{m} \cdot \mathrm{K})]}\end{array}$ & $\begin{array}{c}\text { Measured transfer } \\
\text { factor } \mathcal{T} \text { with } \\
\text { aluminium foils on } \\
\text { the surfaces } \\
{[\mathrm{W} /(\mathrm{m} \cdot \mathrm{K})]}\end{array}$ & $\begin{array}{c}\text { Surface } \\
\text { emissivity } \\
\text { effect \% }\end{array}$ \\
\hline 1 & 0.0452 & 0.0419 & -7.30 \\
\hline 2 & 0.0453 & 0.0421 & -7.06 \\
\hline 3 & 0.0452 & 0.0420 & -7.08 \\
\hline 4 & 0.0453 & 0.0420 & -7.28 \\
\hline 5 & 0.0453 & 0.0421 & -7.06 \\
\hline
\end{tabular}


Table 2 Effect of the emissivity on expanded polystyrene: aluminium foils inside the material

\begin{tabular}{|c|c|c|c|}
\hline $\begin{array}{c}\text { pecimen } \\
\text { number }\end{array}$ & $\begin{array}{c}\text { Measured transfer } \\
\text { factor } \mathcal{T} \text { without } \\
\text { aluminium foils } \\
{[\mathrm{W} /(\mathrm{m} \cdot \mathrm{K})]}\end{array}$ & $\begin{array}{c}\text { Measured transfer } \\
\text { factor } \mathcal{T} \text { with } \\
\text { aluminium foils } \\
\text { inside }[\mathrm{W} /(\mathrm{m} \cdot \mathrm{K})]\end{array}$ & $\begin{array}{c}\text { Surface } \\
\text { emissivity } \\
\text { effect \% }\end{array}$ \\
\hline 1 & 0.0452 & 0.0407 & -9.96 \\
\hline 2 & 0.0453 & 0.0408 & -9.93 \\
\hline 3 & 0.0452 & 0.0410 & -9.29 \\
\hline 4 & 0.0453 & 0.0408 & -9.34 \\
\hline 5 & 0.0453 & 0.0409 & -9.71 \\
\hline
\end{tabular}

The last set of measurements was made on the same polystyrene panels cut with the aluminium foil inside but in this second case also the main surfaces were covered with aluminium reflective foils. The results are summarized in Table 3: the decreasing of the transfer factor is about $13 \%$ due to the sum of the two effects.

Table 3 Effect of the emissivity on expanded polystyrene: aluminium foils on the external surfaces and inside the material

\begin{tabular}{|c|c|c|c|}
\hline $\begin{array}{c}\text { Specimen } \\
\text { number }\end{array}$ & $\begin{array}{c}\text { Measured transfer } \\
\text { factor } \mathcal{T} \text { without } \\
\text { aluminium foils } \\
{[\mathrm{W} /(\mathrm{m} \cdot \mathrm{K})]}\end{array}$ & $\begin{array}{c}\text { Measured transfer } \\
\text { factor } \mathcal{T} \text { with } \\
\text { aluminium foils } \\
\text { inside and on the } \\
\text { surfaces }[\mathrm{W} /(\mathrm{m} \cdot \mathrm{K})]\end{array}$ & $\begin{array}{c}\text { Surface } \\
\text { emissivity } \\
\text { effect } \%\end{array}$ \\
\hline 1 & 0.0452 & 0.0392 & -13.27 \\
\hline 2 & 0.0453 & 0.0394 & -13.02 \\
\hline 3 & 0.0452 & 0.0390 & -13.72 \\
\hline 4 & 0.0453 & 0.0391 & -13.69 \\
\hline 5 & 0.0453 & 0.0392 & -13.47 \\
\hline
\end{tabular}

Figure 2 summarizes the different measured transfer factors in the four different measurement conditions. It is possible to see immediately the great improving of the thermal performance of the material when using aluminium foils on the main surfaces or interposing inside the panel or both.

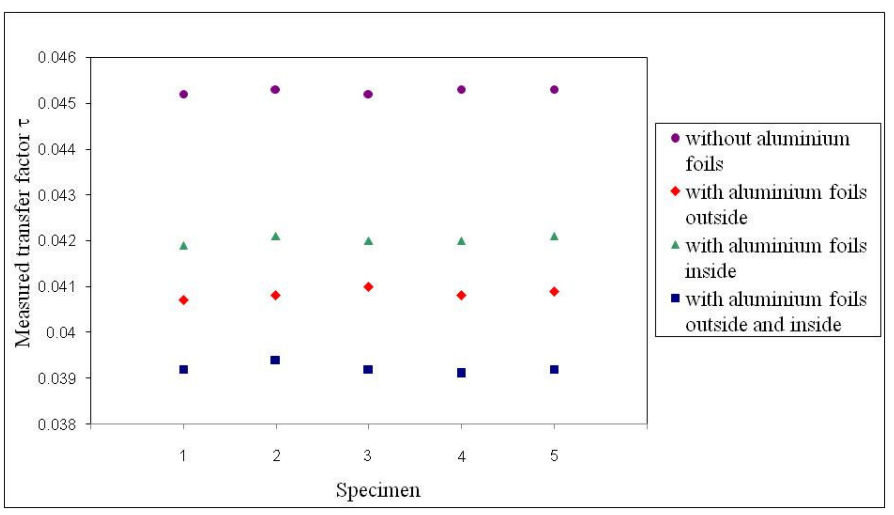

Figure 2 Measured transfer factor with different testing conditions
VALIDATION OF THE MODEL

The second step was the validation of the model described by Equation 4. At first it was necessary to identify the parameters $B^{\prime}$ and $S$ ' while $A, T_{\mathrm{m}}$ and $\rho$ were well known.

\section{MEASUREMENT OF $\boldsymbol{S}^{\prime}$}

The samples were measured in the Bavarian Centre for Applied Energy Research of Wurzburg using two spectrometers in the wavelength range from $1.4 \mu \mathrm{m}$ to $36 \mu \mathrm{m}$ which is decisive for the radiative thermal transport at ambient temperature. For measuring the spectral directionalhemispherical transmittance and reflectance several thin platelets of each foam specimen were cut. The diameter of the platelets is $16 \mathrm{~mm}$.

The samples are mounted into a proper sample holder and placed in the opening of an integrating sphere which is coupled to the spectrometer. Figure 3 shows the configurations of the integrating sphere for transmittance and reflectance measurements. The sample is irradiated normal to the surface and the radiation reflected into the front side hemisphere or transmitted into the rear side hemisphere is measured for the transmittance or reflectance spectra, respectively Figure 3.

From the spectral directional-hemispherical transmittance and reflectance the spectral effective specific extinction coefficient $e^{*}{ }_{A}$ and the spectral effective albedo $\omega^{*}{ }_{\Lambda}$ of each specimen was calculated using a certain solution of the equation of radiative transfer, the so called three-flux solution. The three-flux solution allows to quantify the radiative transfer through scattering and absorbing media as well as to determine the spectral scattering and absorption coefficients of the investigated specimens.

Several samples with different thickness were measured in order to consider eventual inhomogeneities in the specimen and to guarantee a sufficiently good average measurement value. For calculating the spectral effective specific extinction coefficient $e^{*}{ }_{\Lambda}$ the mass per area $\mathrm{m}^{2}$ of each sample was determined.
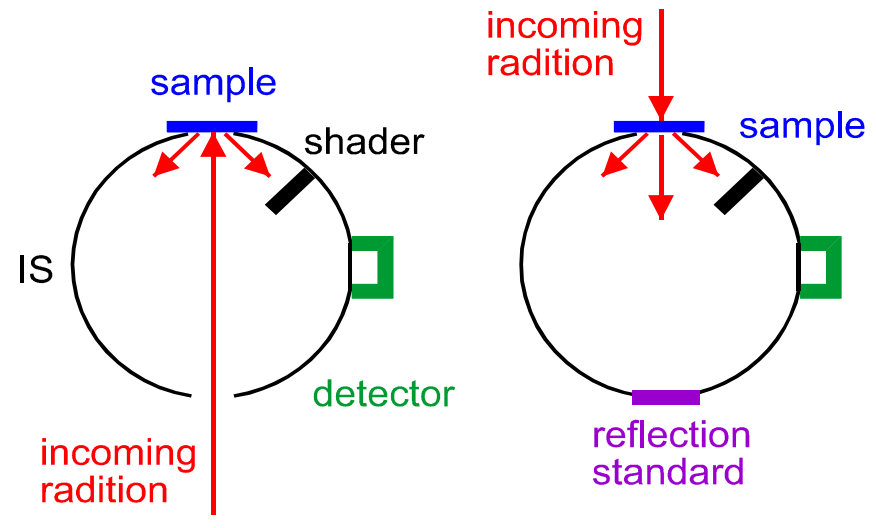

Figure 3 Measurement setup for determining the directional hemispherical transmittance and reflectance 


\section{Spectral extinction coefficient}

The spectral specific extinction coefficient $e_{A}$ is a measure for the attenuation of radiation within the specimen. It includes scattering and absorption processes within the material. The influence of anisotropic scattering on radiative transfer can be enclosed by scaling to the so called effective quantities, marked with a star $\left(s^{*}, e^{*}{ }_{A}\right.$ und $\left.\omega^{*}{ }_{A}\right)$. The spectral effective specific extinction coefficient $e^{*}$ is given by the sum of the spectral effective specific scattering coefficient $s^{*}{ }_{\Lambda}$ and spectral specific absorption coefficient $a_{\Lambda}$.

\section{Total extinction coefficient}

In scattering and absorbing media the total effective specific extinction coefficient as a function of temperature $e^{*}(T)$ is obtained by integrating the spectral effective specific extinction coefficient $e^{*}{ }_{A}$ using the Rosseland weight function $f_{\mathrm{R}}(\Lambda, T)$ :

$\frac{1}{e^{*}}=\frac{\int_{0}^{\infty} \frac{1}{e^{*} \Lambda} \cdot f_{R}(\Lambda, T) \cdot \mathrm{d} \lambda}{\int_{0}^{\infty} f_{R}(\Lambda, T) \cdot \mathrm{d} \lambda}$

The obtained results are summarized in the following Figure 4

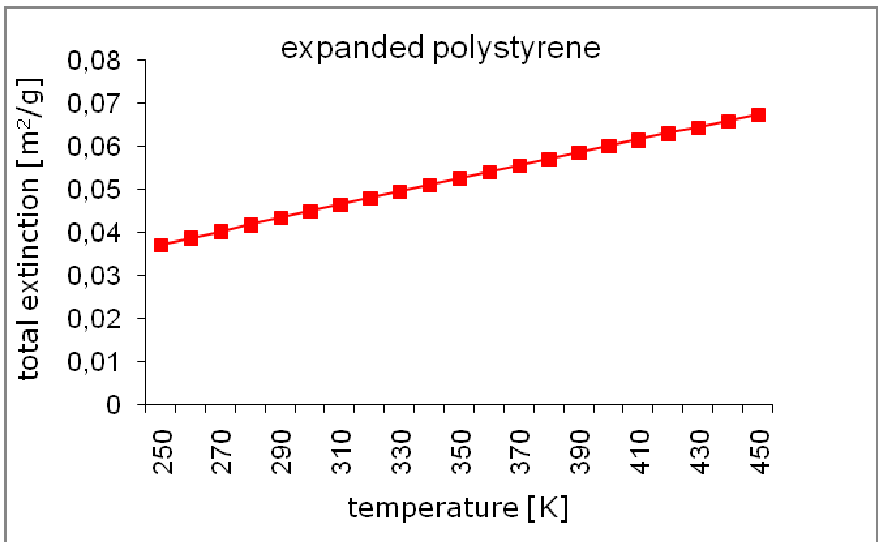

Figure 4 Total extinction coefficient for expanded polystyrene

Once identified all the parameters appearing in the interpolating equation, measured data were then compared with Equations 4. For low density expanded polystyrene we used the value $B^{\prime}=0.0057 \mathrm{~m}^{3} / \mathrm{kg}$ that was obtained with the least square analysis of many experimental data, as it is possible to find in a previous work [12], while the Rosseland total extinction coefficient $1 / \mathrm{e}^{*}$ was divided by $3 / 4$ to obtain the value of $S^{\prime}$ as requested for high optical thicknesses as in our case:

$S^{\prime}=\frac{4}{3} \frac{1}{e^{*}}$
Once known the parameter to introduce in the model a comparison with the experimental data was made. At first were compared the ones obtained from the measurements of polystyrene boards without any reflective foils (surface emissivity $\varepsilon=0.91$ ). As it is possible to see from Table 4 the agreement of the model with experimental data remains within the apparatus accuracy. The transfer factor may be considered equal to the thermal transmissivity, due to the fact that there is no "thickness effect".

Then the comparison was made with the other experimental data. It was clear that the change of the surfaces

Table 4 Comparison between the measured transfer factor and the calculated thermal transmissivity: surface emissivity

$$
\varepsilon=0.91
$$

\begin{tabular}{|c|c|c|c|c|c|}
\hline $\mathrm{N}$. & $\begin{array}{c}\text { Measured } \\
\text { transfer } \\
\text { factor } \mathcal{T} \\
{[\mathrm{W} /(\mathrm{m} \cdot \mathrm{K})]}\end{array}$ & $\begin{array}{c}\text { Calculated } \\
\lambda \mathrm{r}[\mathrm{W} /(\mathrm{m} \cdot \mathrm{K})]\end{array}$ & $\begin{array}{c}\text { Calculated } \\
\lambda \mathrm{c} \\
{[\mathrm{W} /(\mathrm{m} \cdot \mathrm{K})]}\end{array}$ & $\begin{array}{c}\lambda \mathrm{t}=\lambda \mathrm{r}+\lambda \mathrm{c} \\
{[\mathrm{W} /(\mathrm{m} \cdot \mathrm{K})]}\end{array}$ & Diff. \% \\
\hline 1 & 0.0452 & 0.01896 & 0.02635 & 0.04531 & 0.25 \\
\hline 2 & 0.0453 & 0.01898 & 0.02635 & 0.04533 & 0.06 \\
\hline 3 & 0.0452 & 0.01897 & 0.02635 & 0.04532 & 0.27 \\
\hline 4 & 0.0453 & 0.01907 & 0.02635 & 0.04542 & 0.26 \\
\hline 5 & 0.0453 & 0.01897 & 0.02635 & 0.04532 & 0.04 \\
\hline
\end{tabular}

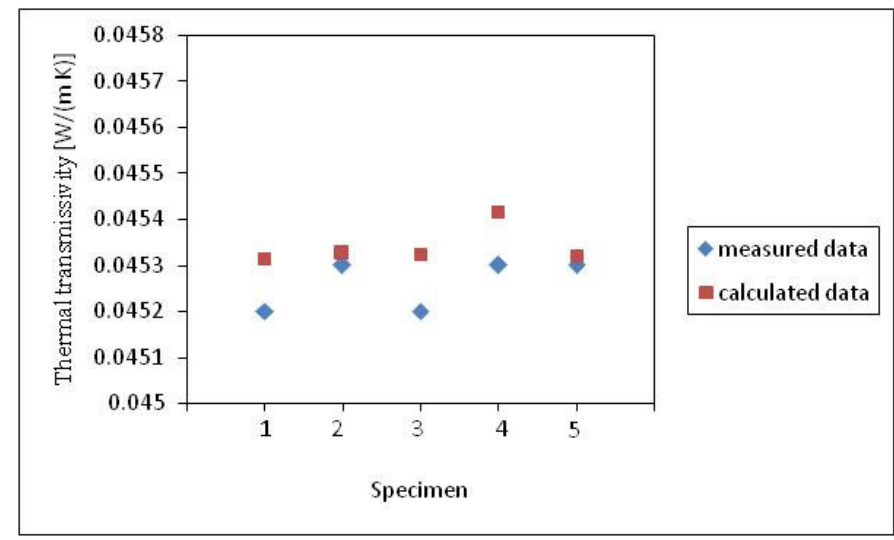

Figure 5 Comparison between the calculated values and the experimental data

emissivity and the interposition of reflective foils have a not negligible influence on the radiation component of the total heat transfer. For this reason the above used model do not fit the experimental data but it is necessary to introduce a corrective coefficient only for the term $\lambda_{\mathrm{r}}$ representing the contribution of radiation.

When there is only a change in the emissivity of the surfaces there is a good agreement with experimental data if the term due to radiation (Equation 3) is divided by 1.2. The results are summarised in Table 5 and in Figure 6. The error of the model in predicting the thermal performance of the material is lower than the accuracy of the experimental apparatus. 
Table 5 Comparison between the measured transfer factor and the calculated thermal transmissivity: surface emissivity $\varepsilon=0.045$

\begin{tabular}{|c|c|c|c|c|c|}
\hline N. & $\begin{array}{c}\text { Measured } \\
\text { transfer } \\
\text { factor } \mathcal{T} \\
{[\mathrm{W} /(\mathrm{m} \cdot \mathrm{K})]}\end{array}$ & $\begin{array}{c}\text { Calculated } \\
\lambda \mathrm{r}[\mathrm{W} /(\mathrm{m} \cdot \mathrm{K})]\end{array}$ & $\begin{array}{c}\text { Calculated } \\
\lambda \mathrm{c} \\
{[\mathrm{W} /(\mathrm{m} \cdot \mathrm{K})]}\end{array}$ & $\begin{array}{c}\lambda \mathrm{t}=\lambda \mathrm{r}+\lambda \mathrm{c} \\
{[\mathrm{W} /(\mathrm{m} \cdot \mathrm{K})]}\end{array}$ & Diff. \% \\
\hline 1 & 0.0419 & 0.01579 & 0.02635 & 0.04214 & 0.57 \\
\hline 2 & 0.0421 & 0.01581 & 0.02635 & 0.04216 & 0.15 \\
\hline 3 & 0.0420 & 0.01582 & 0.02635 & 0.04217 & 0.40 \\
\hline 4 & 0.0420 & 0.01591 & 0.02635 & 0.04223 & 0.55 \\
\hline 5 & 0.0421 & 0.01582 & 0.02635 & 0.04217 & 0.15 \\
\hline
\end{tabular}

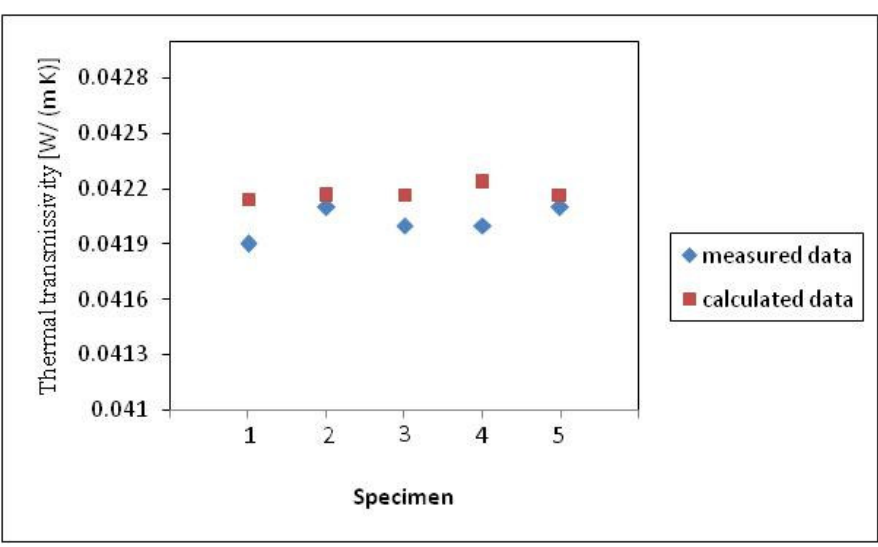

Figure 6 Comparison between the calculated values and the experimental data

On the contrary, when the emissivity of the surfaces remains unchanged but we interpose an aluminium foil inside the specimen between the two slices, our model predict with a very good accuracy experimental data if the term due to radiation is divided by 1.3 . The results are summarised in Table 6 and in Figure 7. Also in this second case the error of the model in the determination of the thermal performance of the material is very low.

Table 6 Comparison between the measured transfer factor and the calculated thermal transmissivity: aluminium foil inside

\begin{tabular}{|c|c|c|c|c|c|}
\hline N. & $\begin{array}{c}\text { Measured } \\
\text { transfer } \\
\text { factor } \mathcal{T} \\
{[\mathrm{W} /(\mathrm{m} \cdot \mathrm{K})]}\end{array}$ & $\begin{array}{c}\text { Calculated } \\
\lambda \mathrm{r}[\mathrm{W} /(\mathrm{m} \cdot \mathrm{K})]\end{array}$ & $\begin{array}{c}\text { Calculated } \\
\lambda \mathrm{c} \\
{[\mathrm{W} /(\mathrm{m} \cdot \mathrm{K})]}\end{array}$ & $\begin{array}{c}\lambda \mathrm{t}=\lambda \mathrm{r}+\lambda \mathrm{c} \\
{[\mathrm{W} /(\mathrm{m} \cdot \mathrm{K})]}\end{array}$ & Diff. \% \\
\hline 1 & 0.0407 & 0.01457 & 0.02635 & 0.04092 & 0.52 \\
\hline 2 & 0.0408 & 0.01458 & 0.02635 & 0.04095 & 0.36 \\
\hline 3 & 0.0410 & 0.01458 & 0.02635 & 0.04093 & -0.17 \\
\hline 4 & 0.0408 & 0.01466 & 0.02635 & 0.04101 & 0.50 \\
\hline 5 & 0.0409 & 0.01458 & 0.02635 & 0.04094 & 0.09 \\
\hline
\end{tabular}

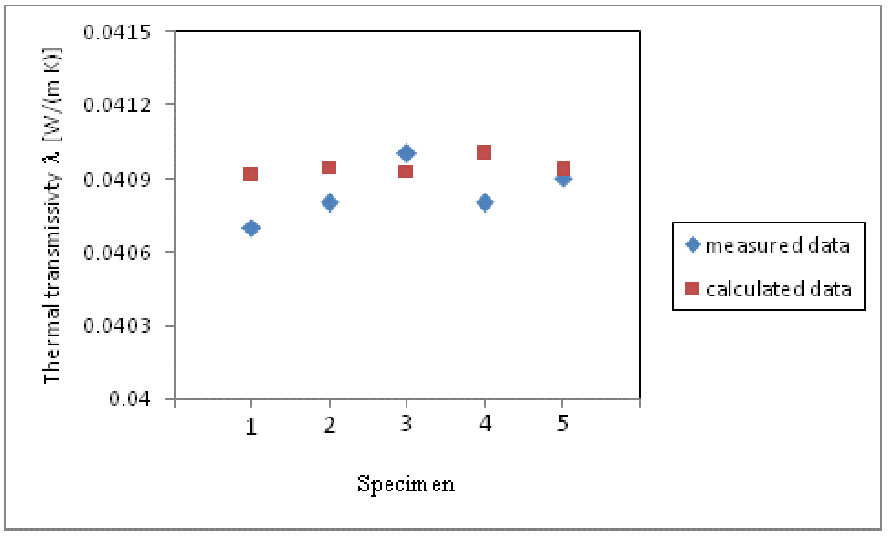

Figure 7 Comparison between the calculated values and the experimental data

In the third case, when there is a change of the emissivity of the surfaces together with an aluminium foil inside the specimen, there is a further decreasing of the thermal transmittance. In this case the term due to the contribution of radiation should be divided by 1.5 . The results are summarised in following Table 7 and in Figure 8. Also in this last case there is a good agreement between the model and experimental data.

Table 7 Comparison between the measured transfer factor and the calculated thermal transmissivity: surface emissivity $\boldsymbol{\varepsilon}=0.045$ and aluminium foil inside

\begin{tabular}{|c|c|c|c|c|c|}
\hline $\mathrm{N}$. & $\begin{array}{c}\text { Measured } \\
\text { transfer } \\
\text { factor } \tau \\
{[\mathrm{W} /(\mathrm{m} \cdot \mathrm{K})]}\end{array}$ & $\begin{array}{c}\text { Calculated } \\
\lambda \mathrm{r}[\mathrm{W} /(\mathrm{m} \cdot \mathrm{K})]\end{array}$ & $\begin{array}{c}\text { Calculated } \\
\lambda \mathrm{c} \\
{[\mathrm{W} /(\mathrm{m} \cdot \mathrm{K})]}\end{array}$ & $\begin{array}{c}\lambda \mathrm{t}=\lambda \mathrm{r}+\lambda \mathrm{c} \\
{[\mathrm{W} /(\mathrm{m} \cdot \mathrm{K})]}\end{array}$ & Diff. \% \\
\hline 1 & 0.0392 & 0.01263 & 0.02635 & 0.03898 & 0.57 \\
\hline 2 & 0.0391 & 0.01265 & 0.02635 & 0.03900 & 0.27 \\
\hline 3 & 0.0390 & 0.01265 & 0.02635 & 0.03900 & 0.01 \\
\hline 4 & 0.0391 & 0.01271 & 0.02635 & 0.03906 & 0.15 \\
\hline 5 & 0.0392 & 0.01265 & 0.02635 & 0.03900 & 0.53 \\
\hline
\end{tabular}

\section{CONCLUSIONS}

In this work the radiative thermal behaviour of a low density expanded polystyrene has been investigated both theoretically and experimentally.

It is well known that for low density insulating materials the measured transfer factor $\mathcal{T}$ is affected by the emissivity of the surfaces bounding the specimen. In accordance with this fact, the results obtained from the measurements of the transfer factor $\mathcal{T}$ pointed out that a change of the emissivity $\varepsilon$ of the surfaces from 0.91 to 0.045 caused a decreasing of the transfer factor of about $7 \%$. 


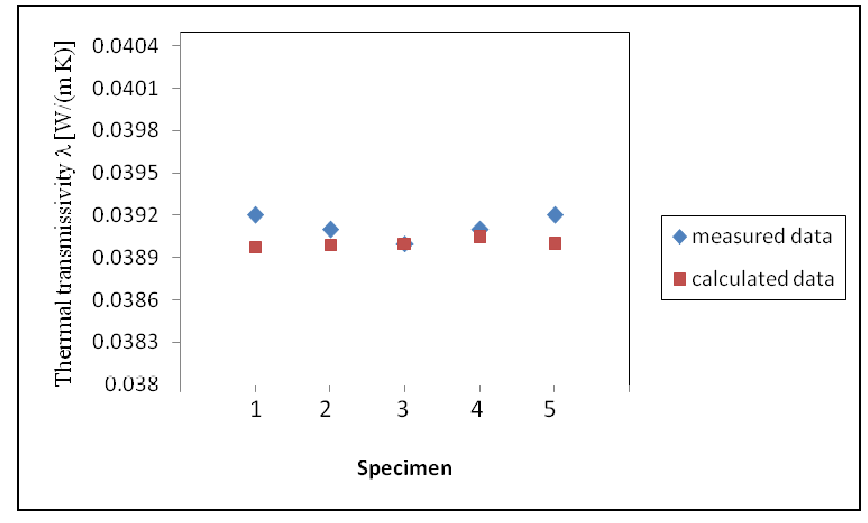

Figure 8 Comparison between the calculated values and the experimental data

It is possible to obtain a further improvement of the thermal behaviour of the material by cutting it into two equal slices and introducing a reflective foil between the material. In this case the improvement of the thermal properties is about $10 \%$. Combining the two things (change of the surface emissivity + reflective foil inside) we have a significant improvement of the thermal behaviour of about $13 \%$.

Furthermore, the cost of the aluminium foils does not affect significantly the final cost: this can be seen as an actual solution for improving the thermal performance of common using insulating materials.

\section{FUTURE WORK}

The dependence of the heat transfer with respect to the number of slices $n$ will be investigated in the near future and a corrective factor of the model will be given for this material as a function of $n$. This study will be also extended to polyester fibre.

\section{REFERENCES}

[1] Campanale, M., De Ponte, F., "The IFT Heat Flow Meter Apparatus", Atti del $44^{\circ}$ Congresso Nazionale ATI, Cosenza, 1989, p. VII 3-14, 1989.

[2] M. C. Arduini and F. De Ponte, "Combined Radiation and Conduction Heat Transfer in Insulating Materials", in Proceedings, 10th ETPC, High Temperatures-High Pressures, Vol 19, p. 237, 1986.
[3] M. Campanale and F. De Ponte, "Thermal Modelling of Cellular Plastic Materials IncludingRegularly distributed Non-Homogeneities", Congresso Nazionale ATI, Gaeta, pp V-31, 1991.

[4] M. Campanale e and F. De Ponte, "Polyester Fibre Boards as Reference Materials in the Measurements of the Thermal Resistance" BCR Certification Report, Bruxelles, 1992.

[5] H. C. Hamaker, "Radiation and Heat Conduction in Light Scattering Materials", Philips Research Reports 2, 55, 1947.

[6] B. Larkin and S.W. Churchill, "Heat Transfer by Radiation Through Porous Insulations", AIChE Journal, 5, p. 467, 1959.

[7] M. Campanale, "Determination of Thermal Resistance of Thick Specimens by means of Guarded Hot Plate or Heat Flow Meter", Congresso Nazionale ATI, Taormina, vol. I, p. 441, 1993.

[8] CEN/TC 89 N 173: Thermal insulating Materials for Buildings - Determination of Thermal Resistance of Thick Specimens - Guarded Hot Plate and Heat Flow Meter Method.

[9] Schuetz, M. Glicksman, L. "A Basic Study of Heat Transfer through Foam Insulation”. Journal of Cellular Plastics, p.114, 1984.

[10] Bonacina, C., Campanale, M., Moro, L., "Experimental and Theoretical Investigation on the Influence of Surface Emissivity on the Thermal Conductivity of Insulating Materials", $13^{\text {th }}$ International Heat Transfer Conference, Sydney, Australia, 2006.

[11] Bonacina, C., Campanale, M., Moro, L., "Further Experimental and Theoretical Investigation on the Influence of Surface Emissivity on the Thermal Conductivity of low Density Insulating Materials", $19^{\text {th }}$ National $\& 8^{\text {th }}$ ISHMT-ASME Heat and Mass Transfer Conference, JNTU Hyderabad, India, 2008.

[12] Campanale, M., De Ponte, F., Moro, L., "Theoretical characterization of non homogeneous plastic materials", $44^{\circ}$ Eurotherm Seminar, Advances in thermal insulation, Espinho (Portugal), p. 65, 1995. 